\title{
Uso do Aplicativo Slice Fractions como Objeto de Aprendizagem Móvel para Matemática: Relato de Experiência de uma Aula sobre Frações
}

\author{
Elvis Medeiros de Melo \\ Instituto Metrópole Digital - Universidade Federal do Rio Grande do Norte (UFRN) \\ Av. Sen. Salgado Filho, 3000 - Lagoa Nova, CEP: 59.078-970 - Natal - RN - Brasil \\ elvismedeiros.mm@gmail.com
}

\begin{abstract}
This paper presents the experience report of a fraction class with a fifth grade class in a Natal, Rio Grande do Norte. The objective of the activity was to reinforce concepts about fraction seen previously, with the activities of the educational app Slice Fractions. The use of the Bring Your Own Device (BYOD) played an important role, since students spend a lot of time with their smartphones. We applied a questionnaire to know the students' perception about the practice. $90 \%$ of the students considered the practice to be significant, reinforcing that activities based on educational software, such as education-oriented apps potentiate the learning.
\end{abstract}

Resumo. Este trabalho apresenta o relato de experiência de uma aula sobre fração com uma turma de quinto ano em um colégio da cidade do Natal, Rio Grande do Norte. O objetivo da atividade foi reforçar conceitos sobre fração vistos anteriormente, com as atividades do app educativo Slice Fractions. A utilização da proposta Bring Your Own Devide (BYOD) teve papel importante, visto que os alunos passam muito tempo com seus smartphones. Aplicamos um questionário para saber a percepção dos alunos sobre a prática. $90 \%$ dos alunos consideraram a prática significativa, reforçando que atividades com base em softwares educativos, como apps voltados para a educação potencializam a aprendizagem.

\section{Introdução}

Atualmente, muito se tem feito para tornar o ensino de Matemática mais dinâmico e produtivo, mas alguns conteúdos acabam caindo na monotonia. $\mathrm{O}$ ensino de frações não foge a esse fato. Ao longo do ensino fundamental, os números naturais deixam de ser suficientes para resolver todos os problemas [Brasil 1997], e aos poucos são introduzidos os números racionais, principalmente quando falamos de partes de um inteiro.

Inserir softwares educacionais em uma determinada aula requerem pontos a serem resolvidos pelos professores, como a definição de quais tecnologias são adequadas para determinada aula, a aquisição delas pelos alunos, se os softwares são gratuitos ou pagos, se haverá necessidade do uso da internet, se são adequados aos dispositivos dos alunos, entre outras. Em seguida, vem o domínio técnico-pedagógico, saber usar cada ferramenta. Tudo isso é complexo e demorado [Moran 2013].

Em relação as Tecnologias Digitais de Informação e Comunicação (TDICs), elas estão presentes em nosso cotidiano e cada vez mais ubíquas. Isto se deve, principalmente, a popularidade adquirida por dispositivos móveis como laptops, tablets e, especialmente, os smartphones. A partir de uma análise de políticas públicas de 
VII Congresso Brasileiro de Informática na Educação (CBIE 2018)

Anais dos Workshops do VII Congresso Brasileiro de Informática na Educação (WCBIE 2018)

inserção de TDICs nas escolas brasileiras, Borba e Lacerda (2015) promovem um debate sobre a utilização de smartphones nas salas de aula e argumentam em favor do que denominaram "Projeto Um Celular por Aluno". De acordo com os autores, tais dispositivos móveis já estão na escola pelas mãos dos alunos o que deve ser considerado, dentre outras vantagens, pela redução os custos de implementação de uma política pública. O fato é que a proposta do BYOD (bring your own device - traga seu próprio dispositivo) parece se disseminar à revelia de qualquer orientação pedagógica.

Sabe-se que muitas são as dificuldades reconhecidas no campo da matemática e, algumas delas, fazem com que os alunos desistam em meio a sua jornada. Acredita-se que, com a agregação dos Objetos de Aprendizagem Móveis (OAMs) ao ensino da matemática, em especial o app educativo Slice Fractions da Ululab ${ }^{1}$, trazem inúmeras possibilidades de sucesso nesse ramo. Tal disciplina pode ser trabalhada de forma criativa e de acordo com as dificuldades percebidas pelo professor, por meio de recursos tecnológicos [Andrade e Rodrigues 2016].

Um estudo conduzido por pesquisadores da Universidade de Quebec em Montreal (UQAM) demonstrou que o app Slice Fractions melhorou significativamente o desempenho dos alunos em um curto período de tempo [Boucher-Genesse e Dumont 2015]. O estudo foi conduzido entre 139 alunos do terceiro ano do ensino fundamental, divididos em três grupos: o primeiro recebeu o ensino tradicional; O segundo jogou Slice Fractions em sala de aula, além do ensino tradicional; E o terceiro apenas jogou o jogo em sala de aula. $\mathrm{O}$ segundo e terceiro grupos mostraram maior e mais significativa melhoria no desempenho do que os alunos que receberam apenas o ensino tradicional, indicadas através de um teste.

Esta pesquisa foi realizada com uma turma do $5^{\circ}$ ano do Ensino Fundamental Anos Iniciais. No dia da prática, estavam presentes dez alunos com idades entre 9 e 12 anos. O objetivo deste artigo é relatar a experiência com a manipulação do Slice Fractions, no qual os estudantes realizaram atividades associadas ao conhecimento teórico sobre o conceito de fração, proposta dos OAMs.

\section{Metodologia}

O público-alvo deste relato de experiência foram alunos do quinto ano de uma escola da cidade do Natal, Rio Grande do Norte. Todo o conteúdo de frações foi abordado antes da prática com este app educativo. A princípio, foi perguntado quem possuía smartphone, pois a escola não possui recursos tecnológicos. Como alternativa, pensamos na perspectiva BYOD. Dos dez alunos presentes no dia, oito disseram que possuíam com o sistema operacional Android instalado, porém das mais diversas versões.

A escolha do app seguiu parâmetros gerais e poder ser instalado em qualquer um dos celulares dos alunos. O app educativo Slice Fractions ${ }^{2}$ requer versão 4.0 ou superior do Android. Todos os smartphones dos alunos estavam enquadrados nessa faixa. Em momento anterior, pedimos para os alunos instalasse o app em seus smartphones, pois realizaríamos atividades na aula de matemática.

Realizamos as atividades em duplas, para integrar os alunos que não possuíam o smartphone. Para as duplas avançarem na atividade, deveriam trabalhar em equipe. $\mathrm{O}$ professor atuou como mediador, observando a validade das informações passadas pelos alunos quanto aos níveis do jogo, assim como as suas conclusões. Para a atividade,

\footnotetext{
${ }^{1}$ Para mais informações, consultar <http://ululab.com/slice-fractions/>. Último acesso em: 20/06/2018

${ }^{2}$ Disponível em: <https://goo.gl/iHbsX5>. Último acesso: 20/06/2018.
} 
VII Congresso Brasileiro de Informática na Educação (CBIE 2018)

Anais dos Workshops do VII Congresso Brasileiro de Informática na Educação (WCBIE 2018)

combinamos que quem chegasse na última atividade da parte 5 do app venceria. Para avançar de forma correta, deveriam iniciar pelo tutorial e seguir, por ordem numérica, as atividades do jogo. As atividades do Slice Fractions se dividem em cinco ambientes: 1.Compartilhamento; 2.Símbolos; 3.Componentes; 4.Comparação; 5.Solução de Problemas.

Apesar do software possuir atividades pagas, as atividades grátis foram os objetos para a nossa análise. No final, foi aplicado um questionário de satisfação para saber a opinião dos alunos sobre a atividade. Com o questionário, analisamos as questões: 1.Você gostou de usar o celular em sala de aula?; 2. Você achou os desafios fáceis ou difíceis?; 3. A aula foi divertida?. Analisaremos as respostas na próxima sessão.

\section{Resultados e Discussões}

No grupo do whatsapp da turma, os alunos relatavam sua empolgação e ansiedade para participar da aula, pois seria a primeira experiência usando o celular para fins educacionais.

No caminhar da atividade, os alunos trabalharam não só os conceitos de fração presentes nas atividades do app, mas também a cooperação e gestão de seu tempo, além de disciplina e trabalho em grupo. Na Figura 1, vemos os alunos interagindo com o jogo.

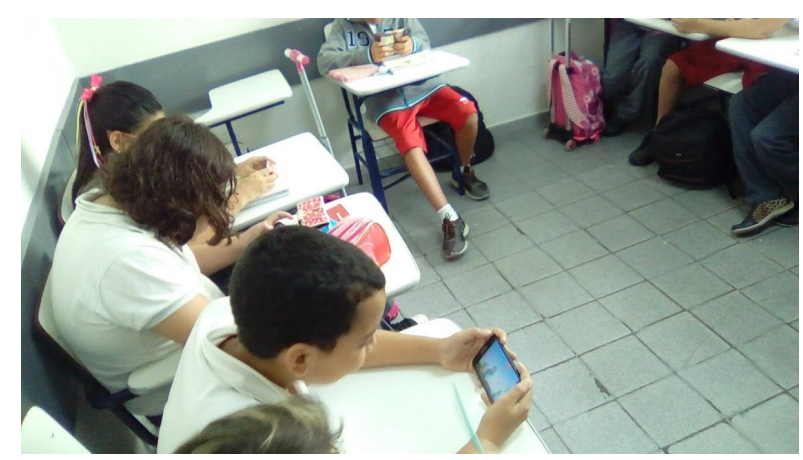

Figura 1. Alunos da turma interagindo com o app educativo Slice Fractions.

Observamos que, para o êxito na conclusão da atividade, o aluno precisou entender a ideia de fração, pois um movimento errado faria com que ele retornasse todo o caminho de volta até chegar nessa fase novamente.

$\mathrm{Na}$ medida que as fases avançavam, o app trazia mais desafios. A partir de um momento, ele não dava mais dicas da resolução, cabendo ao aluno descobrir onde ele deveria repartir a figura para que tivesse a fração correspondente. Percebemos o entusiasmo dos alunos com a atividade, pois ele estava fazendo matemática, ou seja, usando conceitos da matemática para resolver situações-problema práticos, de acordo com comentários de alunos durante a resolução dessa atividade.

Alguns alunos tiveram dificuldade na medida que avançavam de fases. As atividades requerem maior entendimento do processo prático das frações, que não foi vista por eles. Há uma relação direta desse modo como eles estudaram o conteúdo de frações, ou seja, através de aulas expositivas, com a dificuldade enfrentada na realização da atividade. Isso reforça a necessidade de práticas com apps que potencializam a aprendizagem de conceitos matemáticos na fase de contextualização dos conteúdos, pois dá sentido à prática de ensino.

Analisando as respostas dos alunos às perguntas do questionário ao final da prática, observamos que $80 \%$ gostou de usar o smartphone em sala de aula. Além disso, 
VII Congresso Brasileiro de Informática na Educação (CBIE 2018)

Anais dos Workshops do VII Congresso Brasileiro de Informática na Educação (WCBIE 2018)

$70 \%$ acharam os desafios de médios para fáceis, e 30\% acharam os desafios difíceis. Isso mostra que mesmo sendo uma atividade de retomada de conteúdo, alguns alunos fazem abstrações de maneira diferente. 90\% dos alunos acharam a aula divertida. Podemos inferir esse resultado por ser a primeira vez que eles usaram esse recurso dentro da sala de aula, e também pelo relato durante as aulas de que em casa a grande parte do tempo deles é utilizando esse dispositivo. Já em relação à pergunta 3, acreditamos que os resultados são por causa da natureza da atividade. Como se trata de algo novo, que eles não estão acostumados, pode ser fator importante para esse resultado.

\section{Considerações Finais}

Existem contribuições muito importantes dos apps educativos para a aprendizagem de conceitos matemáticos. Quando alinhados ao currículo de Matemática, promovem aprendizagem significativa em relação à compreensão dos registros abstratos deste componente curricular e superam a desmotivação dos alunos. A composição de dispositivo móvel sob a perspectiva BYOD ajudou na superação dos maiores desafios das escolas que é fazer que o aluno aprenda da melhor maneira possível. Os educadores devem ver as tecnologias de modo positivo, e que por mais complexo que seja inserir as ferramentas tecnológicas na sala de aula.

O uso do Slide Fractions foi positivo na medida em que serviu como contextualizador do conteúdo de frações, dando sentido a prática. Os professores necessitam de formação permanente que os auxilie a utilizar apps educativos como estratégia pedagógica de apoio à construção de conhecimentos matemáticos, assim como o uso dos equipamentos móveis na escola com a finalidade de inovar no processo de desenvolvimento e avaliação da aprendizagem dos alunos.

\section{Referências}

Andrade, G.O. ; Rodrigues, C.K. (2016). Objetos de Aprendizagem na Educação Estatística: "Vem Aprender". In: V Congresso Brasileiro de Informática na Educação (CBIE 2016), Uberlândia/MG. Anais dos Workshops do V Congresso Brasileiro de Informática na Educação (CBIE 2016).

Borba, M. de C.; Lacerda, H. D. G. (2015). "Políticas públicas e tecnologias digitais: um celular por aluno”. Educação Matemática Pesquisa (EMP), São Paulo, v.17, n.3, p.490-507.

Boucher-Genesse, F.; Dumont, Jean-Guillaume (2015). Ululab: une entreprise spécialisée dans la création de jeux vidéo éducatifs pour appareils mobiles. Magazine Inter, Vol. 13, no 1, printemps.

Brasil (1997). Secretaria de Educação Fundamental. Parâmetros curriculares nacionais: matemática /Secretaria de Educação Fundamental. - Brasília :MEC/SEF, 142p.

Moran, José Manoel (2013). A educação que desejamos. Novos desafios e como chegar lá. Campinas: Papirus. 